\title{
Histoplasma-associated inflammatory pseudotumour of the kidney mimicking renal carcinoma
}

\author{
Michael A. den Bakker • Natascha N. T. Goemaere • \\ Juliëtte A. Severin • J. L. Nouwen • \\ Paul C. M. S. Verhagen
}

Received: 26 October 2008 /Revised: 19 November 2008 / Accepted: 3 December 2008 / Published online: 6 January 2009

(C) The Author(s) 2008. This article is published with open access at Springerlink.com

\begin{abstract}
A 56-year-old female, originally from Suriname, with an otherwise unremarkable previous medical history was found to have a renal mass highly suspicious for renal cancer for which a nephrectomy was performed. Within the kidney, a tumourous mass was found which, on histological examination, showed an inflammatory pseudotumour caused by Histoplasma capsulatum. Further investigations revealed an idiopathic $\mathrm{CD} 4{ }^{+}$lymphopenia. Mass lesions mimicking a malignant tumour caused by infection with Histoplasma have rarely been described. To the best of our knowledge, this is the first report of a Histoplasmaassociated inflammatory pseudotumour mimicking cancer occurring in the kidney
\end{abstract}

\section{A. den Bakker}

Department of Pathology,

Erasmus MC-University Medical Center Rotterdam,

PO Box 2040, 3000 CA Rotterdam, The Netherlands

\section{J. A. Severin · J. L. Nouwen}

Department of Medical Microbiology and Infectious Diseases,

Erasmus MC-University Medical Center Rotterdam,

PO Box 2040, 3000 CA Rotterdam, The Netherlands

P. C. M. S. Verhagen

Department of Urology,

Erasmus MC-University Medical Center Rotterdam,

PO Box 2040, 3000 CA Rotterdam, The Netherlands

M. A. den Bakker $(\bowtie)$

Josephine Nefkens Institute,

Room Be204a, Erasmus MC, P.O. Box 2040, 3000 CA

Rotterdam, The Netherlands

e-mail: m.denbakker@erasmusmc.nl

Present address:

N. N. T. Goemaere

Stichting PATHAN, St. Franciscus Hospital,

Kleiweg 500, 3045 PM,

Rotterdam, The Netherlands
Keywords Histoplasma capsulatum · Inflammatory pseudotumour $\cdot$ Immunodeficiency $\cdot$ Kidney neoplasms

\section{Introduction}

Infection by Histoplasma capsulatum, a dimorphic fungus endemic in North and South America, Africa and Asia, may go unnoticed in otherwise healthy individuals or may cause symptoms in a number of ways. Histoplasmosis diagnosed in patients outside of endemic areas invariably results from prior infection during stay or residence in an endemic area [1]. Although most infections with $H$. capsulatum remain subclinical or are self-limited, severe disease may occur in debilitated and immunodeficient individuals. In immunosuppressed individuals, primary infection or reactivation of an old infection may lead to disseminated histoplasmosis [1]. Mass lesions resulting from Histoplasma infection have rarely been described, usually involving the lungs, central nervous system, adrenal glands and rarely the colon. These mass lesions may, on occasion, simulate a malignant tumour. In this case report, we describe a renal fibroinflammatory pseudotumour closely mimicking a malignant tumour caused by H. capsulatum. A diagnosis of idiopathic $\mathrm{CD}^{+}$lymphopenia was established after laboratory investigation and the occurrence of additional lesions caused by H. capsulatum. To the best of our knowledge, Histoplasmaassociated pseudotumour mimicking renal cancer has not been previously reported in the literature.

\section{Clinical history}

A 56-year-old female from the Dutch West Indies domiciled in The Netherlands for 35 years presented with 
malaise and severe weight loss over a period of several months without fever or night sweats. She did not smoke or use alcohol. She had previously been diagnosed with type 2 diabetes and hypertension. Laboratory investigations revealed a mild normocytic anaemia. Further investigations revealed a mass in the left kidney clinically and radiologically consistent with a malignant tumour (Fig. 1). Because of the high index of suspicion, a biopsy was not obtained and a nephrectomy was performed. The nephrectomy specimen revealed a $7-\mathrm{cm}$ pink homogenous mass in the upper pole, bulging out of the surface of the kidney but not extending through the capsule (Fig. 2).

\section{Materials and methods}

The resected specimen was processed routinely. HE sections and special stains [PAS and silver stains (Grocott)] were ordered for selected slides.

\section{Results}

Histology of the mass revealed a circumscribed nonencapsulated lesion composed of fibro-histiocytic inflammatory tissue composed of plump fibroblasts and histiocytes admixed with lymphocytes and plasma cells (Fig. 3a). On high magnification, microorganisms, measuring approximately $3-5 \mu \mathrm{m}$, were identified which were predominantly intracellular in location. The organisms were more easily identified in the PAS and silver (Grocott) stains (Fig. 3b, c). Based on the size of the organisms and the tinctorial properties, a diagnosis of $H$. capsulatum-associated inflammatory pseudotumour was established. An ulcerated oral lesion was found at repeated physical examination, in addition to several skin lesions. The oral lesion was biopsied

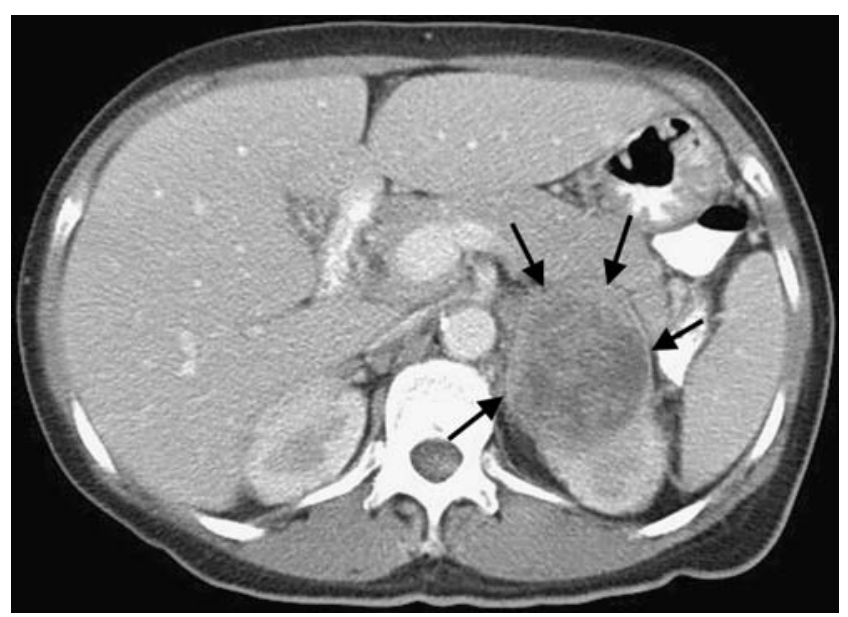

Fig. 1 CT image at the level of the kidneys showing a mass (arrows) bulging out of the upper pole of the left kidney

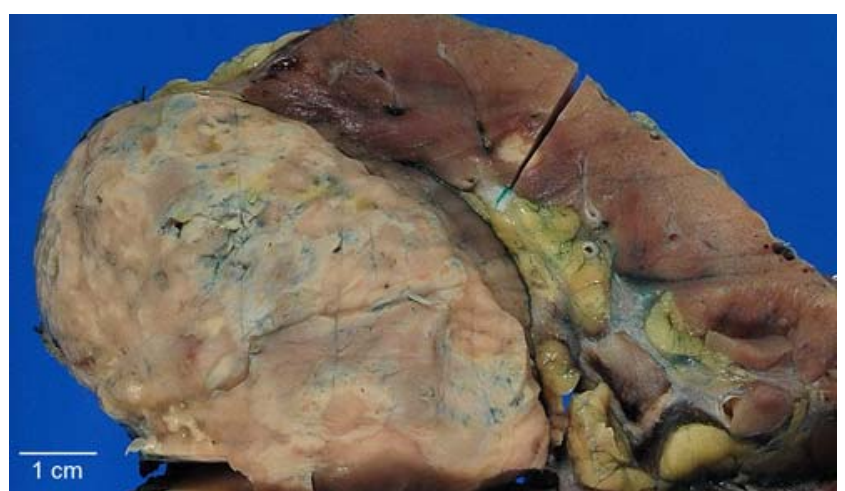

Fig. 2 Nephrectomy specimen. A pink circumscribed mass is seen bulging into, but not penetrating, the renal capsule

and histology again revealed $H$. capsulatum, which subsequently was confirmed by culture; the skin lesions showed granulomatous inflammation consistent with Histoplasma infection. Imaging revealed an adrenal lesion consistent with a Histoplasma abscess in the right adrenal gland. $H$. capsulatum polysaccharide antigen was detected in urine $(1.23 \mathrm{ng} / \mathrm{ml}$; positive, low). A diagnosis of disseminated histoplasmosis was established. Further tests aimed at establishing an underlying immunodeficiency syndrome revealed a low CD4 count (total T cell count $0.22 \times 10^{9} / \mathrm{L}$, CD- 4 count $0.06 \times 10^{9} / \mathrm{L}, \mathrm{CD}-8$ count $0.15 \times 10^{9} / \mathrm{L}$ ). Results of serological tests for antibodies to HIV-1 and HIV-2 were negative. Idiopathic $\mathrm{CD} 4^{+}$lymphopenia was considered the

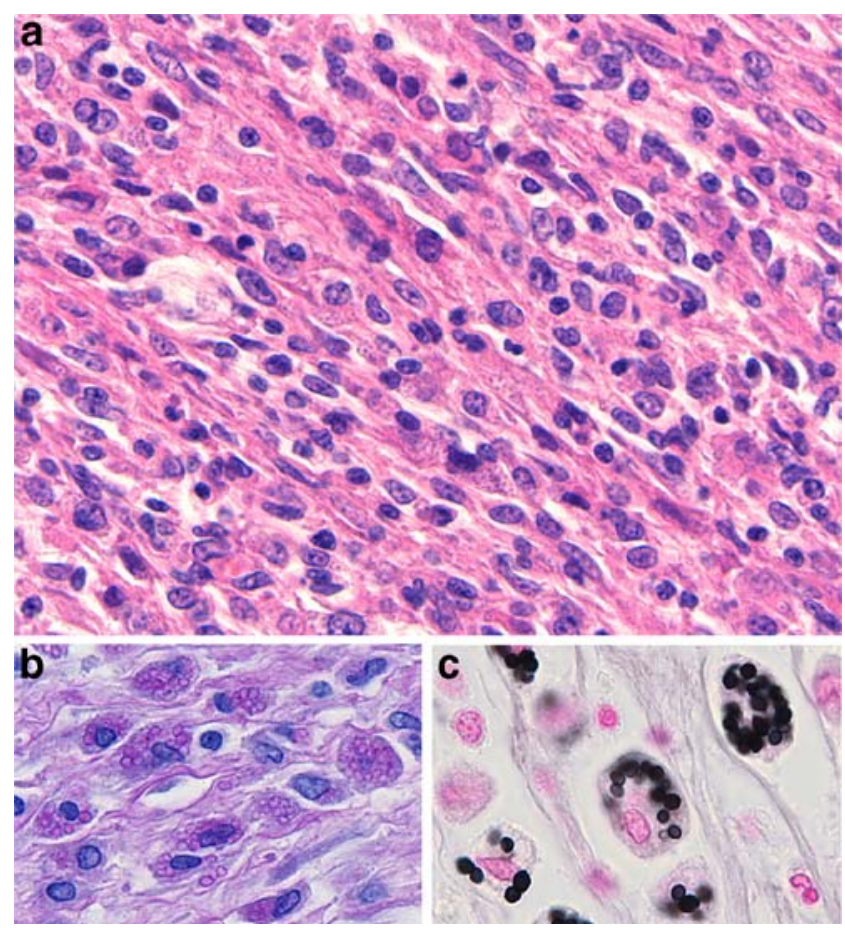

Fig. 3 Histology of the renal mass. a A cellular histiocytic infiltrate is seen, admixed with lymphocytes. The cytoplasm has a granular aspect caused by numerous intracellular Histoplasma organisms. PAS diastase (b) and Grocott (c) stains 
cause of the immunodeficiency leading to disseminated histoplasmosis.

The patient was treated with itraconazole. Her condition improved and oral and skin lesions completely resolved. After 9 weeks, the patient was placed on maintenance therapy. Repeat laboratory analysis showed persistent low CD4 counts.

\section{Discussion}

H. capsulatum infection usually remains asymptomatic in the majority of people. If disease develops in immunocompetent individuals, it is commonly a self-limited flu-like illness. Heavy exposure may result in pneumonic disease and may be associated with rheumatic disease. Involved sites in Histoplasma infection may include lungs, lymph nodes, bone marrow, heart, spleen, liver, adrenal gland, central nervous system, gastrointestinal tract, genitourinary tract and the skin [2]. Occasionally, infection by Histoplasma may lead to the formation of mass lesions which may be confused with malignant disease. In the lung, Histoplasma nodules are known as "histoplasmomas" and are commonly found in a sub-pleural location. Radiologically, histoplasmomas are described as coin lesions, and similar lesions are caused by Mycobacteria (tuberculoma) and Coccidioides immitis (coccidioidoma). However, in areas where Histoplasma is endemic, these lesions are generally well recognised and are unlikely to be confused with malignancy, particularly when tell-tale calcifications are present [3]. Mass lesions caused by Histoplasma infection may also occur in the central nervous system, including the spinal cord, and here can radiologically simulate a neoplasm [47]. Diffuse enlargement of the adrenal glands without a definable mass is not uncommon in Histoplasma infection [8]. Mass lesions or strictures simulating cancer caused by Histoplasma infection have been described as one of four patterns of colonic disease and appear particularly common in AIDS [9, 10]. In these cases, the diagnosis is often delayed until surgical resection and pathological examination. The more common ulcerating lesions caused by Histoplasma may also lead to an erroneous diagnosis of malignancy as has been described in the larynx [11, 12]. The histology of Histoplasma infection, be it as ulceroinflammatory lesions or as pseudotumours, is similar. A mixed inflammatory infiltrate develops, mainly composed of histiocytes and lymphocytes, admixed with neutrophils, eosinophils and lymphocytes. The microorganisms are predominantly observed intracellularly in macrophages $[10,13]$. An exaggerated form of pseudotumour which may be caused by Histoplasma is mediastinal fibrosis. Although organisms are often not demonstrated in tissue, a relentless fibrosing reaction develops, encasing vital mediastinal structures ultimately with a fatal outcome [14-16].
Immunodeficiency predisposes to Histoplasma infection or reactivation, which, as evidenced in the case described, here may occur decades after residing in an endemic area. Although, low CD4 counts predisposing to symptomatic and disseminated histoplasmosis may result from HIV infection or may be idiopathic. It has also been demonstrated that CD4 depletion may result from Histoplasma infection; anti-fungal treatment of a patient with disseminated histoplasmosis resulted in restoration of $\mathrm{CD} 4$ counts [17].

Although renal involvement by Histoplasma is a recognised complication in renal transplant patients, as an interstitial nephritis or rarely as (necrotising) papillitis, renal mass lesions have not been previously described [18]. In the case described here, the preoperative suspicion of malignancy was sufficient to opt for nephrectomy. It is uncertain whether the renal mass would have resolved on antifungal treatment had the diagnosis been established by biopsy.

In conclusion, the case presented here of a renal fibrohistiocytic Histoplasma-associated pseudotumour expands the spectrum of mass lesions caused by this organism in immunosuppressed individuals.

Acknowledgements The authors wish to thank Prof. Sebastian Lucas, Dept. of Pathology, St Thomas' Hospital, London for expert review of the histology described in this report.

Conflict of interest The authors declare that they do not have a conflict of interest.

Open Access This article is distributed under the terms of the Creative Commons Attribution Noncommercial License which permits any noncommercial use, distribution, and reproduction in any medium, provided the original author(s) and source are credited.

\section{References}

1. Wheat LJ (2006) Histoplasmosis: a review for clinicians from non-endemic areas. Mycoses 49:274-282

2. Kennedy CC, Limper AH (2007) Redefining the clinical spectrum of chronic pulmonary histoplasmosis: a retrospective case series of 46 patients. Medicine (Baltimore) 86:252-258

3. Goodwin RA Jr, Snell JD Jr (1969) The enlarging histoplasmoma. Concept of a tumor-like phenomenon encompassing the tuberculoma and coccidioidoma. Am Rev Respir Dis 100:1-12

4. Vakili ST, Eble JN, Richmond BD, Yount RA (1983) Cerebral histoplasmoma. Case report. J Neurosurg 59:332-336

5. Venger BH, Landon G, Rose JE (1987) Solitary histoplasmoma of the thalamus: case report and literature review. Neurosurgery 20:784-787

6. Wheat LJ, Batteiger BE, Sathapatayavongs B (1990) Histoplasma capsulatum infections of the central nervous system. A clinical review. Medicine (Baltimore) 69:244-260

7. Tan V, Wilkins P, Badve S, Coppen M, Lucas S, Hay R, Schon F (1992) Histoplasmosis of the central nervous system. J Neurol Neurosurg Psychiatry 55:619-622 
8. Lerttumnongtum P, Muttarak M, Visrutaratna P, Ya-In C (2004) Imaging features of unusual adrenal masses. Australas Radiol 48:107-113

9. Lee JT, Dixon MR, Murrell Z, Konyalian V, Agbunag R, Rostami S, French S, Kumar RR (2004) Colonic histoplasmosis presenting as colon cancer in the nonimmunocompromised patient: report of a case and review of the literature. Am Surg 70:959-963

10. Suh KN, Anekthananon T, Mariuz PR (2001) Gastrointestinal histoplasmosis in patients with AIDS: case report and review. Clin Infect Dis 32:483-491

11. Mave V, Mushatt D (2008) A case of laryngeal histoplasmosis mimicking carcinoma with a review of the literature. J La State Med Soc 160:160-163

12. Phatak AM, Bhattacharya I, Misra V, Prabhu AM, Natraj U (2006) Disseminated histoplasmosis mimicking laryngeal carcinoma from central India - a case report. Indian J Pathol Microbiol 49:452454
13. Kahi CJ, Wheat LJ, Allen SD, Sarosi GA (2005) Gastrointestinal histoplasmosis. Am J Gastroenterol 100:220-231

14. Goodwin RA, Loyd JE, Des Prez RM (1981) Histoplasmosis in normal hosts. Medicine (Baltimore) 60:231-266

15. Goodwin RA, Nickell JA, Des Prez RM (1972) Mediastinal fibrosis complicating healed primary histoplasmosis and tuberculosis. Medicine (Baltimore) 51:227-246

16. Schowengerdt CG, Suyemoto R, Main FB (1969) Granulomatous and fibrous mediastinitis. A review and analysis of 180 cases. J Thorac Cardiovasc Surg 57:365-379

17. Rhew DC, Goetz MB, Louie MH (1995) Reversible CD4 ${ }^{+} \mathrm{T}$ lymphocyte depletion in a patient who had disseminated histoplasmosis and who was not infected with human immunodeficiency virus. Clin Infect Dis 21:702-703

18. Kedar SS, Eldar S, Abrahamson J, Boss J (1988) Histoplasmosis of kidneys presenting as chronic recurrent renal disease. Urology $31: 490-494$ 